\title{
The Applied Talents Training Mode of Material Engineering Specialty in Civil Engineering Background
}

\author{
Zai-bo LI, Tu-sheng HE and Yong-ping ZHANG \\ Shaoguan University, Shaoguan, Guangdong Province, 512005, China
}

\begin{abstract}
Keywords: Local universities, Material engineering specialty, Talents training mode.
\end{abstract}
\begin{abstract}
Nowadays, many school-running concepts of local universities and talents cultivation can't combine closely with market requirements and labor employment, so the supply-demand contradiction in difficult employment for college graduates and difficult recruitment of specialized talents for industrial development arises. The applied cultivating goal and the optimized talents cultivation model should be confirmed clearly. Meanwhile, the applied teaching links and the construction of teaching teams and resources should be strengthened, so as to overall cultivate the applied talents with strong innovative spirit and practical ability.
\end{abstract}

\section{Introduction}

Materials, information and energy sources are perceived as the three backbones for national economy in the 21st century, which have played important role in the construction of national economy, the construction of national defense and the people's life. Materials are the material basis for people's living and development, which mainly contains metal materials, inorganic nonmetallic materials, organic polymeric materials and composite materials. The construction materials in China now have basically completed industrial upgrading with the feature of modernization and large-scale production, so the demand for professionals of certain specialty is steady. In addition, nowadays the inorganic nonmetallic materials industry is in the crucial period of industrial structural transformation, because the supply-demand contradiction between the graduates' difficult employment and difficult recruitment of professionals. Now the school-running models of material engineering specialty are almost: professional entrance-relevant employment, which confined the students to the basic knowledge and skills of material specialty. At the same time, the higher education in China has developed rapidly for more than ten years, and the universities are no longer the "ivory tower" which connects less with society. For these reasons, the traditional talents training modes are no longer suitable for the diversified development situation in the employment opportunities for the undergraduates of material engineering specialty in Chinese colleges and universities.

For the above reasons, the present cultivating goals should equip the students with the basic knowledge of material engineering specialty and the specialized knowledge of civil engineering specialty, so as to cultivate the engineering talents for materials and civil engineering industries in the exploitation, detection, maintenance and strengthening of civil engineering material and the organization and management of construction in civil engineering.

\section{General Idea on the Teaching Reform}

\section{Optimize the Personnel Cultivating Program}

With the guidance of the basic requirement of the relevant national engineering education accreditation, the optimizing of talent training program regards the improvement of students' employment rates and quality as the ultimate purpose. Meanwhile, it is necessary to promote the fusion of knowledge structure in professionals and civil engineering industry, and carry out modular teaching to realize the students' cultivation in levels and directions. In this way, the students can have the preliminary market consciousness, further develop their knowledge structure, so as to establish the students' engineering concept and improve their employment ability. 
As the precondition for the guidance suggestions of specialty construction in relevant national material specialties, the curricula of civil engineering will be offered, such as Building Architecture, Foundation Engineering, Construction Technique, and Green Building Materials, etc. Encourage the students of material engineering specialty minor the civil engineering specialty can promote the fusion of knowledge structure in material engineering professionals and civil engineering industry. Meanwhile, the curricula of Civil Engineering Construction and Construction Management should be brought into the talent training program in the setting of training objective.

\section{Intensify the Practical Teaching Links}

In the experimental teaching links, the multimodal practical teaching system should be established, and the students' engineering practical ability and application ability should be improved. On one hand, resorting to the university's special capital input, the infrastructure construction of practical teaching should be accelerated. For the experiments of specialized basic courses, the normalized infrastructure construction should be strengthened; for the experimental and practical teaching of the specialty, some key large-scale apparatuses should be purchased and the existing apparatuses should be optimized and integrated. These are the hardware support for establishing the practical teaching system which is closely related with the theoretical teaching. Meanwhile, the practical teaching system is on different levels, that is to say, from simplicity to complexity, from singularity to synthesis.

On the other hand, various social resources should be made full use of to improve the quality of practical teaching. It includes two points: The cooperation with the bases of production, learning and research should be deepened, and the innovative model of bilateral talents cultivation with the cooperation of universities and enterprises. The measures are as follows: guiding the specialized practice and training together; establishing the research and development center or laboratory with the university-enterprise cooperation; the scientific and technological innovation research and the project development should be carried out by students based on the research provided by the enterprises to implement the graduation thesis subject. Thus, the optimal allocation and sharing of resources in the talents cultivation of enterprises and teaching of universities can be fully realized. The experienced engineering talents and management experts of enterprises will be engaged as professional part-time teachers to fill the post of undergraduates' tutors in experimental course, curriculum design, graduation thesis, professional practice, and specialty skills training. Thus, the multi-layered optimal allocation of human resources in specialized teaching on experiment and practice can be realized.

\section{Strengthen the Construction of Teaching Team and Resources}

As for the construction of teaching team: the team, which is equipped with solid specialized level, strong teaching capability, high scientific research attainments, rich constructional experience, spirit of unity and cooperation as well as the reasonable education background, age and professional title structure, should be established.

As for the exploitation of curriculum textbooks, it is necessary to boost the construction of teaching resources. Meanwhile, depending on the network information and multimedia technology, the opening and sharing of teaching resources can be realized by making the distinctive teaching resources, which is mainly focused on videos. And through the reform of curriculum system, the contents of the specialized courses will be compacted and the key teaching points will be emphasized, and therefore specialty characteristics and the needs of social development can be embodied. All of these provide the fundamental guarantee for improving the ability of engineering practice and innovation.

\section{Cultivating the Students' Creative Spirit}

As for the students' drill of innovation and pioneering, the science and technology innovation bases for undergraduates are shaped initially based on various favorable conditions. The students are encouraged to take part in technological interest group and form innovative teams, so that the 
undergraduates' entrepreneurial ability and scientific and technological innovation ability can be cultivated. Such abilities are as follows: hold and join in various scientific activities, such as the competitions of science and technology innovation and entrepreneurship, and turn the second classroom into the important component for the base of talents cultivation in scientific and technological innovation.

\section{Summary}

\section{The Social Evaluation}

From the initial founding of the specialty, improving the quality of teaching and talents cultivation have always been the focus. In the aspects of comparable index, which reflects the teaching quality such as, postgraduate examination and the professional skills competition for students with high level, they should be conducted by real practice and solid work to achieve better grades. For example, the students have obtained excellent results in NECCS (National English Competition for College Students) and CUMCM (China's Undergraduate Mathematical Contest in Modeling). Among the graduates of the past two years, there are many students who were enrolled by the national famous universities in postgraduate examination, and this year the enrollment rate of postgraduate examination reached 18 percent, which is among the best in the engineering majors of our university.

\section{The Talent Training Quality}

The graduates from material engineering are mainly engaged in the practical and research work of inorganic non-metallic materials production, constructional engineering, scientific research and development, and operating management, while few of them are engaged in the civil servant of relevant municipal departments. From the feedback of employing units, the graduates of this specialty are tough, hard-working, solidary, cooperative and responsible, and they are equipped with comprehensive basic theory, solid and normative basic skills, extensive knowledge, and strong adaptation for posts, which gained the higher satisfaction from the employing units.

\section{Acknowledgement}

This research was financially supported by the Foundation of Guangdong Educational Committee (2016[233]) and the Foundation of Shaoguan University (SYJY20171811 \& SYJY 20151653).

\section{References}

[1] Li Guoqiang. A Discussion on the Present Characteristic of China's Higher Education Development, Journal of Higher Education, 2017, (07): 16-22.

[2] Wang Xiangting. Deepening Reform of Talent Training Mode and Enhancing Innovative and Practical Ability of Undergraduates. Experimental Technology and Management, 2014, (09): 19-21.

[3] Chen Guixiang. On the Formation of Innovative and Entrepreneurial Talents Cultivation Mechanism with Linkages among University, Government and Enterprise, University Education Science, 2015, (01): 42-47.

[4] Guo Wenli. Transformation and Construction Training Mode Reform of Application-oriented Engineering Talents in Local Universities with Industry Background, Research in Higher Education of Engineering, 2012, (04): 25-33.

[5] Wu Aihua, LiuXiaoyu. Promoting the Cooperation between Universities and CAS Institutions for Talent Cultivating, Research in Higher Education of Engineering, 2015, (02): 6-9. 